\title{
Letter to the Editor regarding the article "Comparison of intra- and postoperative analgesia and pain perception in robot-assisted vs. open radical prostatectomy"
}

\author{
Mark C. Kendall ${ }^{1}$ (D)
}

Received: 31 December 2019 / Accepted: 4 January 2020 / Published online: 10 January 2020

(c) Springer-Verlag GmbH Germany, part of Springer Nature 2020

\section{Dear Editor}

I read with great interest the article of Knipper et al. in a recent issue of the journal [1]. The authors performed a study on 420 patients undergoing radical prostatectomy and concluded that when comparing robot-assisted radical prostatectomy (RARP) vs. open retropubic radical prostatectomy (ORP), a small increase in perioperative morphine administration may be expected in patients undergoing RARP procedures. The authors should be applauded for performing a well-designed study in an important topic (e.g., pain and opioid consumption) in patients undergoing surgery [2, 3]. Moreover, the need to identify the highest risk patients so specific preventive analgesic strategies can be tailored to patients who will benefit the most is of great interest in perioperative medicine $[4,5]$.

Nonetheless, there are several points that need to be clarified by the authors to determine the strength of their findings. First, it is unclear if the patients received a standard intraoperative analgesic regimen as this can affect the study outcomes. Second, it is unclear if the patients received a standard postoperative non-opioid analgesic regimen as this can also alter the study results. Last, it would be important to describe if any of the patients received regional anesthesia (i.e., nerve blocks) as part of their multimodal analgesia regimen as this could reduce the post-operative opioid consumption.

This comment refers to the article available online at https://doi. org/10.1007/s00345-019-02938-w.

Mark C. Kendall

mark.kendall@lifespan.org

1 Department of Anesthesiology, Rhode Island Hospital, Warren Alpert Medical School of Brown University, 593 Eddy Street, Providence, RI 02903, USA
I would welcome comments by the authors as this would help to further validate the findings of this important study.

Author contributions The author, MCK designed and prepared the correspondence. MCK approved the final correspondence and attests to the integrity of the original data and analysis reported in the correspondence. MCK takes responsibility for the completeness and accuracy of the content including the final approval of the manuscript.

Funding None.

\section{Compliance with ethical standards}

Conflict of interest The author declares that he has no conflict of interest statement.

\section{References}

1. Knipper S, Hagedorn M, Sadat-Khonsari M, Tian Z, Karakiewicz PI, Tilki D, Heinzer H, Michl U, Steuber T, Breunig F, Zöllner C, Graefen M (2019) Comparison of intra- and post-operative analgesia and pain perception in robot-assisted vs. open radical prostatectomy. World J Urol. https://doi.org/10.1007/s00345-01902938-w

2. Ueshima H, Inamura R, Hiroshi O (2019) Blocking the femoral and lateral femoral cutaneous nerves using an iliac muscle plane block. J Clin Anesth 53:2-3

3. Mateu Arrom L, Gutiérrez Ruiz C, Mayordomo Ferrer O, Martínez Barea V, Palou Redorta J, Errando Smet C (2019) Long-term follow-up after cystectomy for bladder pain syndrome: pain status, sexual function and quality of life. World J Urol 37:1597-1603

4. Elkoundi A, Chouikh C, Baite A, Bensghir M, Bakkali H, Lalaoui SJ (2019) Successful erector spinae plane block without ultrasound guidance in a severely cardiovascular compromised patient. J Clin Anesth 53:50

5. Ohgoshi Y, Fujiki S, Kamata M, Kubo EN (2019) Combined use of peripheral nerve blocks for multilevel spine surgery. J Clin Anesth 53:54

Publisher's Note Springer Nature remains neutral with regard to jurisdictional claims in published maps and institutional affiliations. 